\title{
BMJ Open Intimate partner violence in pregnancy: a cross-sectional study from post-conflict northern Uganda
}

\author{
Susan Clarke (D , ${ }^{1}$ Robyn Richmond, ${ }^{1}$ Eleanor Black, ${ }^{1}$ Helen Fry, \\ James Henry Obol, ${ }^{1,2}$ Heather Worth ${ }^{1}$
}

To cite: Clarke S,

Richmond R, Black E, et al. Intimate partner violence in pregnancy: a cross-sectional study from post-conflict northern Uganda. BMJ Open 2019;9:e027541. doi:10.1136/ bmjopen-2018-027541

- Prepublication history for this paper is available online. To view these files, please visit the journal online (http://dx.doi org/10.1136/bmjopen-2018027541).

Received 09 March 2019 Accepted 20 September 2019

Check for updates

(c) Author(s) (or their employer(s)) 2019. Re-use permitted under CC BY-NC. No commercial re-use. See rights and permissions. Published by BMJ.

${ }^{1}$ School of Public Health and Community Medicine, University of New South Wales, Kensington, New South Wales, Australia

${ }^{2}$ Faculty of Medicine, Gulu University, Gulu, Uganda

Correspondence to

Dr Susan Clarke;

susan.clarke@unswalumni.com

\section{ABSTRACT}

Objectives To determine the prevalence of intimate partner violence (IPV) in pregnancy and to understand associations and determinants.

Design Cross-sectional survey.

Setting Two rural health clinics in post-conflict northern Uganda.

Participants Women attending two rural health clinics for a new service providing cervical cancer screening, who had experienced pregnancy.

Primary and secondary outcome measures Data were collected by a questionnaire using validated questions from the demographic health survey women's questionnaire and the domestic violence module. Data were entered into tablets using Questionnaire Development System software. Bivariate and multivariate logistic regression was performed, using experience of IPV in pregnancy as the dependent variable. SPSS V.25 was used for all analysis.

Results of 409 participant women, $26.7 \%$ (95\% Cl 18.6\% to $35.9 \%$ ) reported having been slapped, hit or beaten by a partner while pregnant. For $32.3 \%(95 \% \mathrm{Cl} 20.2 \%$ to $37.9 \%$ ) of the women the violence became worse during pregnancy. Women who had ever experienced IPV in pregnancy were more likely to have experienced violence in the previous 12 months $(\mathrm{OR} 4.45,95 \% \mathrm{Cl} 2.80$ to 7.09 ). In multivariate logistic regression, the strongest independent associations with IPV in pregnancy were partner's daily drinking of alcohol (OR 2.02, 95\% Cl 1.19 to 3.43 ) and controlling behaviours (OR $1.17,95 \% \mathrm{Cl} 1.03$ to 1.33 ).

Conclusions The women in this study had more exposure to IPV in pregnancy than previously reported for this region. Women's previous experience of intimate partner violence, partner's daily use of alcohol and his controlling behaviours were strong associations with IPV in pregnancy. This study highlights the uneven distribution of risk and the importance of research among the most vulnerable population in rural and disadvantaged settings. More research is needed in local rural and urban settings to illuminate this result and inform intervention and policy.

\section{INTRODUCTION}

The term 'intimate partner violence' (IPV) describes abusive behaviours within an intimate relationship, which may be of a physical, emotional or sexual nature. ${ }^{1}$ The occurrence

\section{Strengths and limitations of this study}

- There is little previous research on intimate partner violence (IPV) in pregnancy in Uganda nor in sub-Saharan Africa, particularly in more remote locations.

- We used a validated standard questionnaire which allows direct comparison with other available data.

- Our questionnaire did not include sexual or emotional IPV in pregnancy.

- Data were self-reported which may be limited by recall bias or cultural bias.

- Generalisability may be limited as we only sampled two health centres.

of physical IPV in pregnancy is of particular concern as women are extremely vulnerable to the effects of abuse during this time. IPV in pregnancy has been associated with numerous adverse maternal and neonatal health outcomes including preterm labour, low birth weight, miscarriage, pyelonephritis, urinary tract infections, caesarean delivery, antepartum haemorrhage, emotional distress and postpartum depression. ${ }^{2-5}$ Affected women are more likely to miss or delay prenatal care, and have increased rates of cigarette smoking, alcohol and substance abuse during pregnancy. ${ }^{2}$

Globally, IPV in pregnancy is more common than many maternal health conditions screened for in antenatal care, such as placenta praevia (2\% to $8 \%$ of pregnancies) and gestational diabetes ( $1 \%$ to $5 \%$ of pregnancies). ${ }^{67}$ Despite this, research on the topic is comparatively minimal. ${ }^{5}$

Research on patterns of violence in pregnancy is insufficient, in particular whether IPV begins, increases or changes during pregnancy. In their review on IPV in pregnancy, Taillieu and Brownridge reported that IPV became more frequent or severe during pregnancy for one in every five women in the studies included in the review. They found 
that a history of pre-existing IPV conferred an increased risk for IPV in pregnancy, which was up to 17 times greater than women without a history of abuse in one study. ${ }^{5}$

Prevalence estimates for IPV in pregnancy vary across settings globally. Analysis of prevalence data from the Demographic and Health Surveys (DHS) and International Violence Against Women Surveys between 1998 and 2007 demonstrated IPV in pregnancy prevalence rates ranging from $2.0 \%$ in Australia to $13.5 \%$ in Uganda. ${ }^{7}$ In many settings, IPV in pregnancy was higher among women aged 15 to 35 , and declined slightly after this age. ${ }^{7}$ The WHO 2005 multi-country study on women's health and domestic violence reported IPV in pregnancy prevalence rates in 10 countries, not including Uganda, ranging from $1 \%$ in Japan to $28 \%$ in Peru. ${ }^{8}$ Populationbased estimates of IPV likely underestimate prevalence in pregnancy, in part because of limited definitions of IPV to physical IPV only and excluding psychological and sexual IPV, and also because of under-reporting by women. ${ }^{9}$ In their systematic review, Taillieu and Brownridge found that the lowest prevalence rates of physical violence in pregnancy were generally reported in population-based studies. ${ }^{5}$

Within sub-Saharan Africa (SSA), prevalence estimates for IPV in pregnancy vary across regions with substantially higher rates reported compared with the DHS and WHO surveys. For example, a systematic review of 13 studies from SSA between 2000 and 2010 reported prevalence rates of IPV in pregnancy ranged from $2 \%$ in Nigeria to $57 \%$ in Uganda, with nine of the 13 studies reporting prevalence rates greater than $27 \% .{ }^{10} \mathrm{~A}$ small number of crosssectional studies from SSA have reported prevalence rates of close to $20 \%$ in South Africa and Ethiopia ${ }^{311}, 27 \%$ in Tanzania ${ }^{4}$ and $66.9 \%$ in Kenya. ${ }^{12}$ These rates are probably conservative, as IPV is considered a private family matter in many SSA countries and some women may not disclose their experiences. ${ }^{13}$

Among male factors, unemployment predicted IPV in pregnancy in a small number of studies, and a relationship between male alcohol consumption and IPV in pregnancy was reported by a number of studies. ${ }^{5}$ A review on IPV in pregnancy in developing countries also found that male alcohol consumption and lower education level among both partners were associated with IPV in pregnancy. $^{14}$

Risk factors for IPV in pregnancy were identified in the 13 SSA cross-sectional studies including: younger age of the woman ${ }^{3415}$, having a history of IPV ${ }^{3}$, lower levels of education $^{4}{ }^{11} 12$, being married ${ }^{4}$, alcohol intake by the partner ${ }^{11} 12$ and living in rural areas. ${ }^{11}$

There is a need for further research on IPV in pregnancy in SSA, which has not been the focus of the majority of research to date. ${ }^{5}$ Research carried out in Uganda on IPV in pregnancy is limited, but existing studies indicate that it is a significant issue. A cohort study of 612 women recruited at Mulago Hospital found that $28 \%$ of women reported IPV by their spouse during pregnancy. ${ }^{16}$ Their risk of low birth weight delivery was nearly four times greater than their counterparts who had not experienced IPV. The study reported that they had a $37 \%$ higher risk of obstetrical complications. In Kaye and colleagues' crosssectional study of 379 women attending antenatal care in Kampala, more than $57 \%$ of women reported moderateto-severe IPV. ${ }^{17}$

The population of Gulu was exposed to 20 years of conflict and mass internal displacement ending in 2006. Many children were exposed to extreme violence and disruption to their schooling with results continuing after their return, previously described as 'social torture'. ${ }^{18}$ Furthermore, the protective social fabric was broken and the space for expression of masculinity narrowed. Men were both perpetrators and victims of violence, often unable to provide for and protect their families. This intersection of masculinity, power, violence and conflict is the subject of ongoing research in post-conflict settings. ${ }^{18}$

In this paper we seek to address the research gap on physical IPV in pregnancy in northern Uganda where research to date in this post-conflict setting is limited. The aim of our research was to determine the prevalence and patterns of IPV experienced by women during pregnancy, and the associated risk or protective factors, in post-conflict northern Uganda.

\section{METHODS}

Our research was a partnership between staff and students of Gulu University, Gulu, Uganda, and University of New South Wales (UNSW), Sydney, Australia. Gulu University requested this research focus on IPV as there were little data for their area. We conducted a cross-sectional behavioural survey designed to capture quantitative information from women about relationships, reproductive health, sexual behaviour, family planning, sexual and physical violence, access to and assessment of health services and knowledge about cervical cancer.

\section{Study design and population}

The study questionnaire was developed using a validated questionnaire from the Uganda 2011 DHS. ${ }^{19}$ Questionnaire Development System software by NOVA Research Company software was used for programming and hosting the questionnaire on tablets, as well as for transforming the data into Statistical Package for the Social Sciences (SPSS) files. Hard copy versions of the questionnaire were also taken into the field as a backup.

Participants had the option of doing the survey alone or with a researcher. However, as the women in our study had low levels of literacy, the interviews were carried out in Acholi by our research team of UNSW and Gulu University staff and Master of Public Health and medical students over 2 weeks in November 2017. Data from the tablets were updated daily in a safe format and stored securely on a server at UNSW.

The leaders of UNSW and Gulu University teams liaised in Australia, in Uganda and remotely to develop the research plan in the year before data collection. 
The UNSW postgraduate student team members were educated in the history and culture of Gulu and trained by the team leaders in respectful confidential interview techniques in seminars before leaving Australia. The student team members were all medical practitioners experienced in women's health and interview techniques. The post-conflict setting and the need for empathetic techniques responsive to the participants was emphasised. A referral pathway for distressed participants was developed. On arrival in Gulu, there was a seminar for all team members. The UNSW team members trained the Gulu team members in interview technique and use of the tablets. Gulu team members observed the UNSW team members and then began data collection under direct supervision. After conducting satisfactory interviews under supervision, the Gulu staff and postgraduate students conducted interviews independently. The team leader supervised the data collection on site and was always available for assistance.

The study population consisted of women aged 16 and over attending two government health clinics in the districts of Gulu and Omoro, northern Uganda. The women were attending a new programme of cervical screening and had experienced pregnancy. The minimum age of 16 was chosen as $19.1 \%$ of Acholi women aged 15 to 19 years have given birth, and this rises in women with low levels of education. We sought and received ethical clearance for women aged 16 and 17 to give informed consent. Our data collection was a single questionnaire and did not place undue burden on the participants. The women completed the survey in about $20 \mathrm{~min}$ while they were waiting to attend the health centre. We explained that their participation was voluntary and they gave verbal and written informed consent, sometimes with a thumbprint if they could not write. The women were keen to participate and we compensated them for their time with a gift of a $1 \mathrm{~kg}$ bar of soap. The interviews were conducted at a distance to others so that neither questions nor answers could be overheard. We did not record participant's names. We had prearranged a pathway for counselling in the health clinic if our questions caused distress, and our team leader was available for any referrals. We emphasised to the women that they could stop the interview at any time and that they could decline to answer any question.

\section{Measures}

The outcome measure was physical IPV in pregnancy. Questions from the Uganda DHS 2011 were used. ${ }^{8}$ Women were asked 'was there ever a time when you were slapped, hit or beaten by (any of) your partner(s) while you were pregnant?' A response of 'yes' to this item was coded as positive for IPV in pregnancy. We also asked in how many pregnancies they were beaten, whether it happened in the last pregnancy and if she was ever punched or kicked in the stomach while pregnant. We also asked if the perpetrator was the father of the child and if they were living together. We did not ask about sexual or emotional violence in pregnancy as we wanted to use the validated survey questions.

Our independent variables included other experience of IPV (lifetime and in the last 12 months) and gender attitudes. These items were also from the domestic violence module of the Uganda DHS, which was based on the WHO guidelines and are described in figure $1 .{ }^{8}$ Experience of different types of IPV was coded 'yes' or 'no', and attitudes were scores collected as continuous variables. Controlling behaviours and woman's agreement with 'good' reasons for a partner to hit his wife are described in figure 1. Woman's attitudes to gender relations were also assessed by asking her to agree or disagree that a good wife always obeys her husband, family problems only be discussed in the family, it is important for a man to show he is boss, a woman should be able to choose her own friends, it's a wife obligation to have sex even if she doesn't feel like it and if a man mistreats his wife others should intervene. We also asked if there were 'good' reasons to refuse sex: if she does not want to, if he is drunk, if she is sick or if he is mistreating her. Covariates for analyses included continuous measures of participant and partner's age, number of children. Categorical measures of education status of partner and participant, contraception, alcohol, employment and education status were also included. We used validated questions from the Uganda DHS $2011^{19}$ for most questions.

\section{Statistical analysis}

We calculated the sample size based on prevalence estimates of women using a family planning method in the last 12 months from the Uganda DHS 2011. Sample size was calculated from a web-based programme using the formula: $\mathrm{n}=\left(\mathrm{Z}^{2} \times \mathrm{P}(1 \mathrm{P})\right) / \mathrm{e}^{2}$ where $\mathrm{Z}=$ the value from standard normal distribution corresponding to the desired confidence level, $\mathrm{P}=$ the expected true proportion and $\mathrm{e}=$ the desired precision of estimate. To calculate the sample size estimate we used a confidence level of 0.95 and the desired precision of estimate of 0.05 . We estimated a sample size of 350 women aged 16 years and over attending either Awach Health Centre Level IV in Gulu district or Lalogi Health Centre Level IV in Omoro district, Uganda. Consecutive sampling was used for all eligible women attending the health clinics.

Direct logistic regression was performed to assess the impact of a number of factors on the likelihood that participant's has experienced IPV in pregnancy. We used bivariate analyses to assess the associations between IPV in pregnancy and participant characteristics. All variables significantly associated with IPV in pregnancy in bivariate analyses were included in the multivariate analysis. Significance tests were two tailed and $\alpha$ was set at 0.05 . We checked for linearity of the logit for continuous variables in the model. All analyses were conducted using SPSS V.25. 


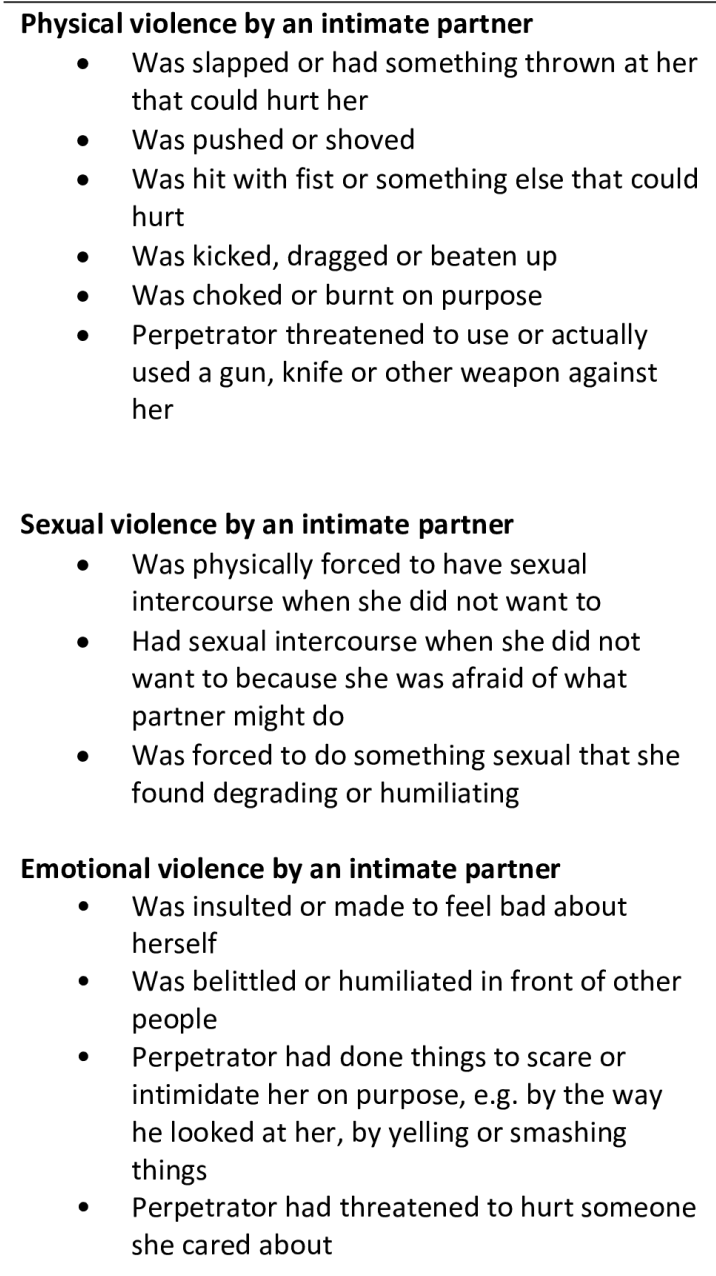

Controlling behaviours by an intimate partner

- He tried to keep her from seeing friends

- He tried to restrict contact with her family of birth

- He insisted on knowing where she was at all times

- He ignored her and treated her indifferently

- He got angry if she spoke with another man

- He was often suspicious that she was unfaithful

- He expected her to ask permission before seeking health care for herself

Physical violence in pregnancy

- Was slapped, hit or beaten while pregnant

- Was punched or kicked in the abdomen while pregnant

- Was perpetrator father of the child

- Was she living with the perpetrator

- Was physical violence in pregnancy less, the same, or better than before pregnancy

\section{Does a man have a good reason to hit his wife if}

- She does not complete her household work to his satisfaction

- She disobeys him

- She refuses to have sexual relations with him

- She asks him whether he has other girlfriends

- He suspects she is unfaithful

- He finds out she has been unfaithful

Figure 1 Intimate partner violence survey categories and questions (following DHS domestic violence module ${ }^{18}$ and WHO multi-country survey ${ }^{8}$.

\section{Public and patient involvement statement}

The public and patients were not involved in the survey design. Research findings will be disseminated within the communities. Community members will be consulted in the design and implementation of any studies that build on this initial study.

\section{RESULTS}

There were 409 women who participated and they had a mean age of 33 years (95\% CI 31.86 to 34.1 years), (see table 1$)$. Most $(77.5 \%, 95 \%$ CI $73.1 \%$ to $81.5 \%)$ women were currently living with a male partner and, of these; the majority $(78.5 \%, 95 \% \mathrm{CI} 67 \%$ to $76 \%)$ were in a household with his relatives. Partners had a mean age of 38.3 years (95\% CI 37.1 to 39.5 years) and most $(71 \%$, $95 \%$ CI $73.1 \%$ to $81.5 \%$ ) were subsistence farmers. More than $70 \%$ (95\% CI $66.5 \%$ to $75.5 \%)$ of the women had been tested for HIV in the previous 12 months and the reported prevalence was $13 \%$ (95\% CI $10.0 \%$ to $16.6 \%$ ). Only $26 \%$ (95\% CI $22.0 \%$ to $30.7 \%$ ) of the participant women reported being able to read, although $80 \%(95 \%$ CI $76.5 \%$ to $84.4 \%$ ) had some schooling. The participants had high prevalence of lifetime exposure to IPV $(78.5 \%$, 95\% CI $74.2 \%$ to $82.4 \%$ ), including $55.7 \%$ (95\% CI $50.5 \%$ to $60.4 \%$ ) who told us that they had experienced IPV in the previous 12 months.

The participants experienced a high prevalence of physical IPV in pregnancy. Over a quarter of the women $(26.7 \%, 95 \%$ CI $22.4 \%$ to $31.2 \%, \mathrm{n}=109)$ reported that they had been slapped, hit or beaten by a partner when pregnant. Of those women, $27.4 \%$ (95\% CI $18.6 \%$ to $35.9 \%, \mathrm{n}=29$ ) reported having been punched or kicked in the stomach when pregnant. The perpetrator of the violence in pregnancy was usually $(90.8 \%, 95 \%$ CI $84.9 \%$ to $96.2 \%)$ the father of the child and almost all (95.3\%, $95 \%$ CI $89.6 \%$ to $98.5 \%$ ) were living together. For $32.3 \%$ ( $95 \%$ CI $20.2 \%$ to $37.9 \%, \mathrm{n}=31$ ) of women, violence increased during pregnancy, for $59.4 \%$ (95\% CI $42.5 \%$ to $62 \%, \mathrm{n}=57)$ violence reduced and for eight $(8.3 \%$, $95 \%$ CI $3.2 \%$ to $14 \%$ ) it remained constant.

We looked for associations between experience of IPV in pregnancy and other participant characteristics (see table 2). Women who had ever experienced physical IPV in pregnancy had significantly increased unadjusted odds 
Table 1 Demographic characteristics of women who have and have not experienced physical IPV in pregnancy

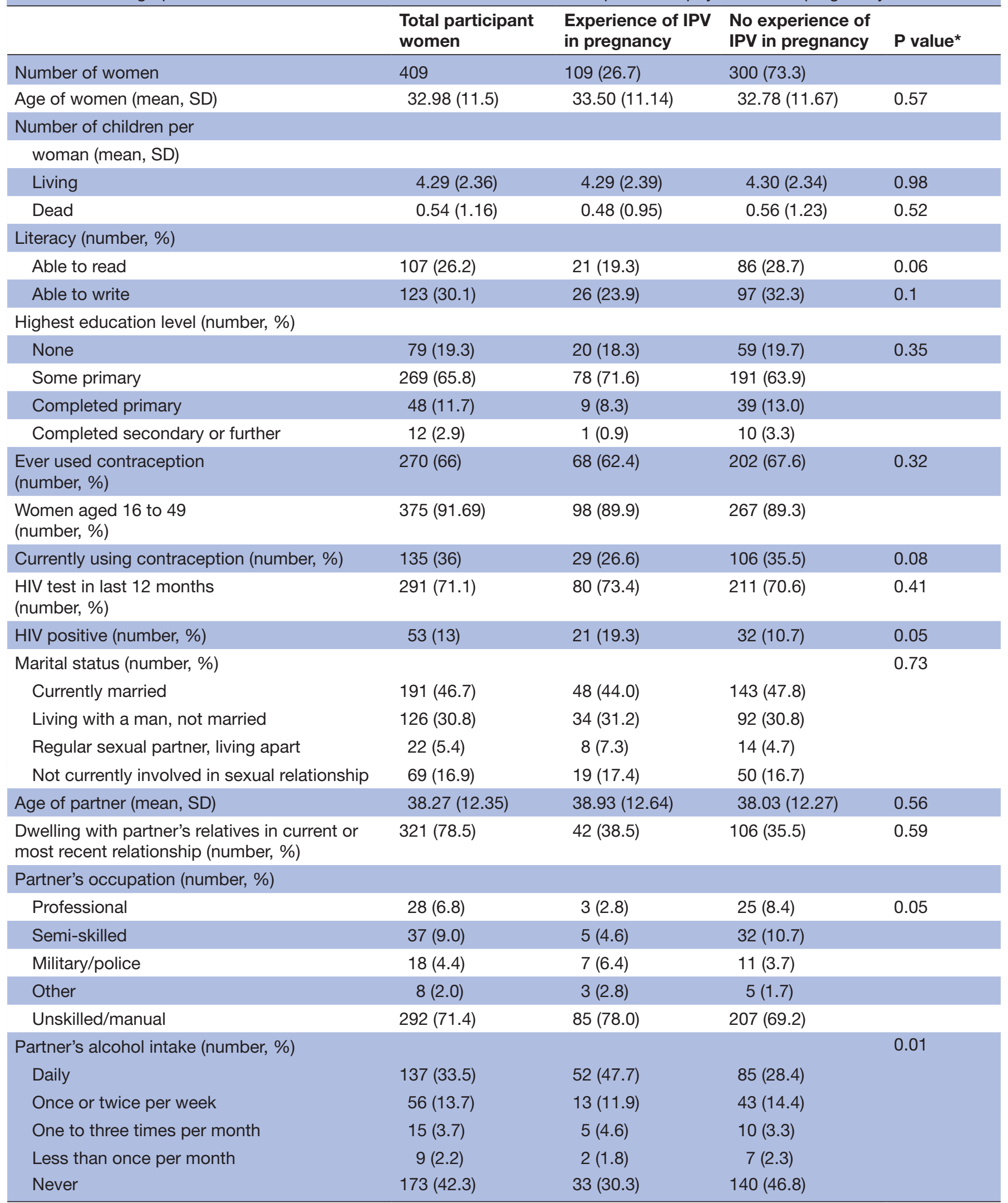

*t-test for continuous variables or $\chi^{2}$ for categorical variables, testing difference between women who had and had not experienced IPV in pregnancy.

IPV, intimate partner violence. 
Table 2 Associations between prior experience of IPV with IPV in pregnancy

\begin{tabular}{llllll}
\hline & $\begin{array}{l}\text { IPV in } \\
\text { pregnancy } \\
\text { N (\%) }\end{array}$ & $\begin{array}{l}\text { No IPV in } \\
\text { pregnancy } \\
\text { N (\%) }\end{array}$ & Unadjusted OR & $\begin{array}{l}\text { 95\% Cl for } \\
\text { unadjusted OR }\end{array}$ & P value \\
\hline $\begin{array}{l}\text { Any IPV (sexual, physical or emotional) } \\
\text { last 12 months }\end{array}$ & $77(70.6)$ & $151(50.3)$ & 2.37 & 1.48 to 3.80 & $<0.01$ \\
$\begin{array}{l}\text { Sexual violence last 12 } \\
\text { months }\end{array}$ & $43(39.4)$ & $72(24)$ & 2.06 & 1.29 to 3.29 & 0.01 \\
$\begin{array}{l}\text { Physical violence last } \\
12 \text { months }\end{array}$ & $66(60.6)$ & $77(25.7)$ & 4.45 & 2.80 to 7.09 & $<0.01$ \\
$\begin{array}{l}\text { Emotional violence last } \\
12 \text { months }\end{array}$ & $65(59.6)$ & $110(37.7)$ & 2.55 & 1.63 to 3.99 & $<0.01$ \\
\hline
\end{tabular}

IPV, intimate partner violence.

of having experienced physical (OR 4.45, 95\% CI 2.80 to 7.09 ), emotional (OR 2.55, 95\% CI 1.93 to 3.99) and sexual (OR 2.06, 95\% CI 1.29 to 3.29) IPV in the previous 12 months compared with those who had not experienced physical IPV in pregnancy. Table 3 shows associations between participant attitudes and partner behaviours. Significant associations are participant agreeing that there were 'good' reasons (such as not completing household tasks to his satisfaction, disobedience, refusing sexual relations, suspicion of unfaithfulness) for husbands to hit their wives and greater number of controlling behaviours by the partner.

Other significant unadjusted associations included partner refusing to use or stopping the use of contraception ((OR 2.23, 95\% CI 1.37 to 3.65) $\mathrm{p}=0.01)$, partner having a physical fight with another man ((OR 2.31,

Table 3 Associations between attitudes and behaviours with IPV in pregnancy

\begin{tabular}{|c|c|c|c|c|c|}
\hline & $\begin{array}{l}\text { IPV in } \\
\text { pregnancy } \\
\text { mean (SD) }\end{array}$ & $\begin{array}{l}\text { No IPV in } \\
\text { pregnancy } \\
\text { mean (SD) }\end{array}$ & $\begin{array}{l}\text { Mean } \\
\text { difference }\end{array}$ & $\begin{array}{l}95 \% \mathrm{Cl} \text { of mean } \\
\text { difference }\end{array}$ & $P$ value \\
\hline $\begin{array}{l}\text { Number of controlling behaviours by partner, } \\
\text { max seven (partner tries to keep from seeing } \\
\text { friends, restrict contact with birth family, } \\
\text { insists on knowing whereabouts, ignores her, } \\
\text { gets angry if she speaks to another man, is } \\
\text { often suspicious of unfaithfulness, expects to } \\
\text { be asked permission to seek healthcare) }\end{array}$ & $4.11(2.07)$ & $3.19(2.0)$ & -0.93 & -1.38 to -0.48 & $<0.01$ \\
\hline $\begin{array}{l}\text { Woman's agreement with 'husband has } \\
\text { a good reason to hit his wife', max eight } \\
\text { (she does not complete household chores, } \\
\text { she disobeys, she refuses sex, she asks } \\
\text { him about girlfriends, he suspects she is } \\
\text { unfaithful, she is unfaithful) }\end{array}$ & 3.09 (1.50) & $2.75(1.56)$ & -0.34 & -0.68 to -0.01 & 0.05 \\
\hline $\begin{array}{l}\text { Woman's attitudes to gender relations, max } \\
\text { six (agrees with following statements: a } \\
\text { good wife always obeys her husband even } \\
\text { if she disagrees, family problems should } \\
\text { only be discussed with people in the family/ } \\
\text { it is important for a man to show his wife } \\
\text { who is the boss/a woman should be able to } \\
\text { choose her own friend's even if her husband } \\
\text { disapproves/it's a wife's obligation to have } \\
\text { sex even if she doesn't feel like it/if a man } \\
\text { mistreats his wife, others outside of the family } \\
\text { should intervene) }\end{array}$ & 3.74 (1.32) & $3.70(1.25)$ & -0.04 & -0.32 to 0.24 & 0.76 \\
\hline $\begin{array}{l}\text { Number of 'good' reasons women give for } \\
\text { refusing sex, max four (if she does not want it, } \\
\text { he is drunk, she is sick, he is mistreating her }\end{array}$ & $2.51(1.12)$ & $2.53(1.20)$ & 0.02 & -0.25 to 0.28 & 0.90 \\
\hline
\end{tabular}

$\mathrm{IPV}$, intimate partner violence. 
Table 4 Logistic regression of associations with physical intimate partner violence in pregnancy

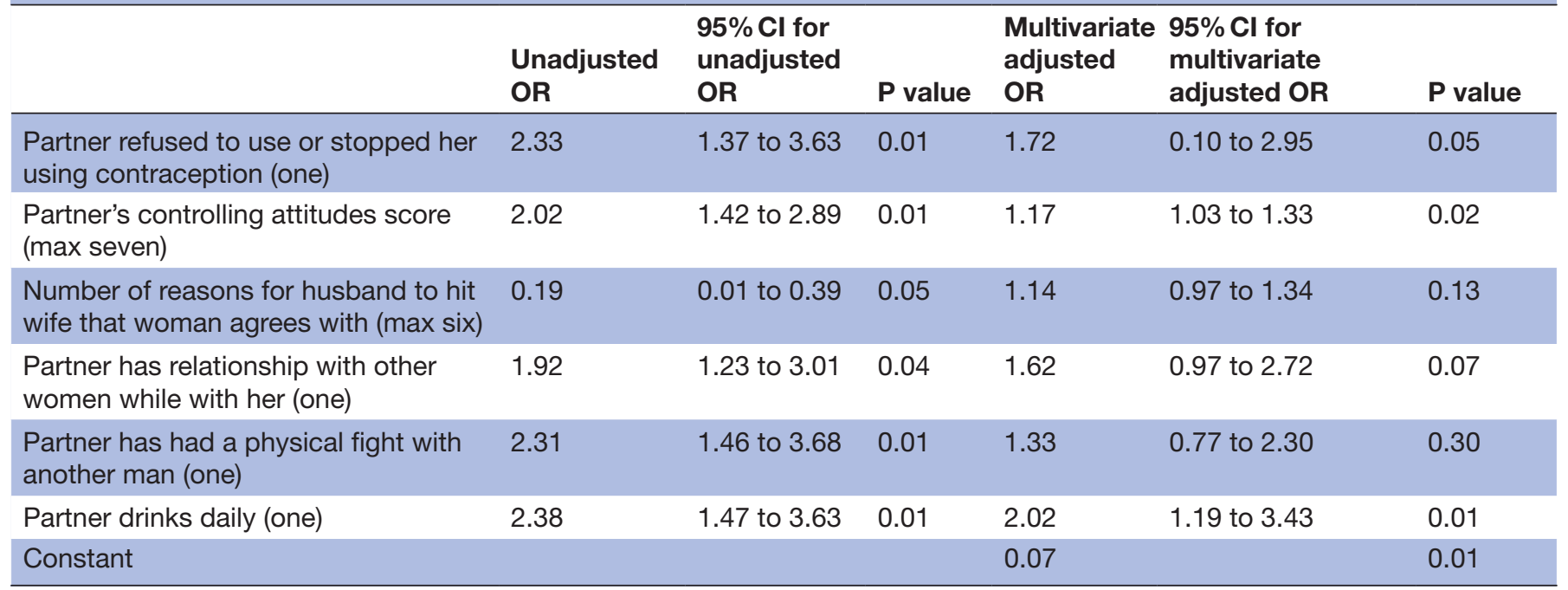

95\% CI 1.46 to 3.68$), \mathrm{p}<0.01)$, partner involved in relationships with other women ( (OR 1.92, 95\% CI 1.23 to 3.01$)$, $\mathrm{p}=0.01)$, partners being drunk on most days ( (OR 2.38, $95 \%$ CI 1.47 to 3.63$), \mathrm{p}=0.01)$. All four of these variable with OR around 2 and narrow CI are likely to be clinically important. Other variables from the literature including women's education level, partner's employment status, age of participant, age of partner and number of children, did not demonstrate evidence of association with the women's experience of physical IPV in pregnancy.

We performed a direct logistic regression using the dependent variable participant's lifetime experience of physical intimate partner violence in pregnancy and six independent variables: participant reporting seeing her partner drunk on most days, participant having knowledge that her partner had been involved in a physical fight with another man, partner refusing to use or stopping her use of contraception, partner's controlling behaviours and partner's concurrent relationships with other women.

The model was statistically significant, $\chi^{2} \quad(6$, $\mathrm{n}=375)=38.52, \mathrm{p}<0.01$, showing that the model was able to distinguish between participants who had and had not experienced IPV in pregnancy. The model was able to explain between $10.4 \%$ (Cox and Snell R square) and $15 \%$ (Nagelkerke $\mathrm{R}$ squared) of the variance in IPV in pregnancy status, and correctly classified $72.4 \%$ of participants. Table 4 shows the unadjusted and adjusted results. Only two of the independent variables (partner's daily alcohol use and partner's controlling behaviours) made a unique statistically significant contribution to the odds of experiencing IPV in pregnancy in this model. The strongest predictor was partner's daily drinking with an adjusted OR of 2.02 (CI 1.19 to 3.43). Partner's controlling behaviours had a low OR of 1.17 (1.03 to 1.33), after all of the other variables in the model were controlled. The other variables, although significant $(\mathrm{p}<0.05)$ on their own, did not independently contribute to the model.

\section{DISCUSSION}

Over one-quarter $(26.7 \%)$ of the women in our study had experienced physical IPV during their pregnancy, which was more than double that of the country-wide prevalence of $11 \%$ in the recent Uganda DHS. ${ }^{20}$ As well, in the DHS results for the Acholi region, where Gulu is situated, the rate was $11.3 \%$ and for all of rural Uganda the rate was $11.4 \% .^{20}$ This suggests that there was a systematic difference in our study population to that surveyed in the DHS. IPV in pregnancy was strongly associated with previous experience of IPV, as well as partner's alcohol intake and his controlling behaviours.

IPV in pregnancy is a uniquely gendered phenomenon. The experience of conflict, loss of land, employment, role of family protector have all disrupted the concept of masculinity in rural Gulu. ${ }^{21}$ The threat to masculinity creates a nexus of violent risk to self in alcohol abuse and to others in family violence which is directly attributable to 'broad processes of social and political subordination within the national context' (Dolan, p315). ${ }^{18}$

Apart from the DHS, there are few other studies in Uganda, but older hospital-based studies record a prevalence of physical IPV in pregnancy similar to our findings. ${ }^{1617}$ Other research in SSA found physical IPV in pregnancy rates of $22.5 \%, 22 \%$ and $9 \%$ in Nigeria, $10.7 \%$ in Tanzania and $36 \%$ in South Africa. ${ }^{22-25}$ Similar studies in other low resource settings such as India (12\%) and Bangladesh $(35.2 \%)$ reveal much lower rates of physical IPV in pregnancy than reported in $\mathrm{SSA},{ }^{26}$ with the exception of a single study in Bangladesh. ${ }^{27}$ Training of research staff and the setting may affect the answers given on IPV questions and contribute to variability of results.

IPV in pregnancy was strongly associated with both lifetime and previous 12 months experience of physical, emotional and sexual IPV in our study. This is a common finding across the literature where IPV in pregnancy is strongly correlated with previous experience of IPV and other forms of violence, particularly in SSA. ${ }^{172526}$ 
The participants lived in two rural areas that were most affected by conflict and where the population was forced into settlement camps. Therefore, post conflict trauma may contribute to the higher rates of IPV in pregnancy that we found.

Although, in some other studies, education has been protective against IPV in pregnancy, in our study education was not associated with IPV in pregnancy. ${ }^{25}$ The women in our study reported less education and less literacy than for the Acholi region in the DHS. The DHS data recorded that $31 \%$ of women in Uganda were unable to read at all, which included $37 \%$ of rural women and $44.7 \%$ of Acholi women. However, $78 \%$ of our participants were unable to read at all. This finding confirms that there is a systematic difference in our study population compared with studies in both the Acholi region and other rural communities in Uganda. During the conflict people with resources moved to the towns and were able to continue their education, while people in rural areas had more disruption to their education. $^{28}$

Daily alcohol use by partners was associated with IPV in pregnancy in this study and in the literature..$^{102627}$ Around half $(49.5 \%)$ of the partners of women who had experienced IPV in pregnancy drank daily compared with $29.8 \%$ of those who had not experienced IPV in pregnancy. Alcohol is a significant known risk of IPV, but it does not fully explain the phenomenon as half of the women who had experienced IPV in pregnancy, including being hit in the stomach, had partners who did not drink regularly, and around one-third (31\%) did not drink at all.

Controlling behaviours by partners had a linear correlation with physical IPV in pregnancy; the greater number of controlling behaviours present the more likely the woman was to experience physical IPV in pregnancy. The number of controlling behaviours was much higher in our study population than in the DHS. In the DHS, $37 \%$ of women in Uganda reported three or more controlling behaviours by their partner, $31 \%$ in the Acholi region and $37 \%$ in rural areas. ${ }^{20}$ However in our study $65.7 \%$ of participants reported three or more controlling behaviours, which included $58.2 \%$ of women who had not experienced IPV in pregnancy and $88.3 \%$ who had experienced IPV in pregnancy. Again, this suggests that there is a systematic difference in our study population compared with the population sampled in the DHS. Although this is mentioned in the literature, controlling behaviours have rarely been measured in IPV research carried out in SSA. ${ }^{10}$ However, Jain $e t a t^{26}$ used the same scale in Bangladesh and found a strong correlation between highly controlling behaviour and all forms of IPV in pregnancy. In their qualitative study in Wakiso district of Uganda, Kaye et $a l^{16}$ found that men's uncertainty with shifting gender power balances and cultural values, along with urban migration and high unemployment, led to gender antagonism and IPV in pregnancy.

\section{Strengths and weaknesses}

Strengths of this research include the use of a standardised questionnaire to allow direct comparison with national data, the large sample size and lack of similar research in Uganda.

Weaknesses of this research included no questions on sexual or emotional IPV in pregnancy, nor questions on previous exposure to other forms of violence. IPV is under-reported and a single questionnaire may not accurately represent prevalence. Our research relied on self-report, so may be subject to recall bias, cultural bias and social desirability bias. We tried to minimise nondisclosure by ensuring anonymity and confidentiality, empathetic interviewer training and private interview settings. Furthermore, the study was only conducted in two health centres in northern Uganda, so may not be representative.

Research in other centres with an expanded questionnaire, along with qualitative data is needed to expand the findings. The high prevalence of IPV in pregnancy reinforces the need for programme to identify women at risk and resources which enhance their protection, options and autonomy.

\section{CONCLUSION}

In the post-conflict setting of rural Gulu, physical IPV in pregnancy is notably more common than in the reported data for the rest of Uganda. The major independent risk factors were daily alcohol use by partner and the number of partner's controlling behaviours. Women who experienced IPV in pregnancy were significantly more likely to have been exposed to lifetime physical, emotional and sexual IPV. The generational effects of conflict, the exposure to violence and the disruption to education and culture are all possible explanations for the differences between rural Gulu and the rest of Uganda and are likely to have contributed to the higher prevalence of IPV in pregnancy. Further research is needed to better understand the association between previous exposure to conflict and IPV in pregnancy and to compare our findings with a study carried out in an urban setting.

Twitter Susan Clarke @susanclarke_1

Contributors We declare that all authors have made substantial contributions. $\mathrm{RR}$, HW and JO conceived the study, developed the protocol and supervised the study. All authors collected data. HF, EB and SC performed the preliminary data analysis. SC and JO performed the final data analysis. All authors contributed to interpretation of results. SC and EB drafted the manuscript and all authors contributed to critical revisions of the manuscript. All authors read and approved the final manuscript.

Funding The authors received funding from the Institute for Global Development (University of New South Wales) and this was used for travel expenses for UNSW staff. The funders had no role in the study design, data collection and analysis, decision to publish or preparation of the manuscript. All authors had full access to all of the data in the study and can take responsibility for the integrity and accuracy of the data.

Competing interests None declared.

Patient consent for publication Not required. 
Ethics approval Ethics approval was obtained from the University of New South Wales Human Research Ethics Committee (HREC HC17795) and the Gulu University Research Ethics Committee (GU REC).

Provenance and peer review Not commissioned; externally peer reviewed.

Data availability statement Data are available upon reasonable request.

Open access This is an open access article distributed in accordance with the Creative Commons Attribution Non Commercial (CC BY-NC 4.0) license, which permits others to distribute, remix, adapt, build upon this work non-commercially, and license their derivative works on different terms, provided the original work is properly cited, appropriate credit is given, any changes made indicated, and the use is non-commercial. See: http://creativecommons.org/licenses/by-nc/4.0/.

ORCID iD

Susan Clarke http://orcid.org/0000-0001-9175-7516

\section{REFERENCES}

1 Krug EG, Mercy JA, Dahlberg LL, et al. World report on violence and health. Geneva: World Health Organization, 2002: 1083-8.

2 Alhusen JL, Ray E, Sharps P, et al. Intimate partner violence during pregnancy: maternal and neonatal outcomes. $J$ Womens Health 2015;24:100-6.

3 Groves AK, Moodley D, McNaughton-Reyes L, et al. Prevalence, rates and correlates of intimate partner violence among South African women during pregnancy and the postpartum period. Matern Child Health J 2015;19:487-95.

4 Mahenge B, Likindikoki S, Stöckl H, et al. Intimate partner violence during pregnancy and associated mental health symptoms among pregnant women in Tanzania: a cross-sectional study. BJOG 2013;120:940-7.

5 Taillieu TL, Brownridge DA. Violence against pregnant women: prevalence, patterns, risk factors, theories, and directions for future research. Aggress Violent Behav 2010;15:14-35.

6 Bloom T, Bullock L, Sharps P. Intimate Partner Violence during Pregnancy. In: Humphreys J, Campbell J, eds. Family violence and nursing practice. $2^{\text {nd }}$ ed. New York: Springer Publishing Company, 2010: 115-54.

7 Devries KM, Kishor S, Johnson $\mathrm{H}$, et al. Intimate partner violence during pregnancy: analysis of prevalence data from 19 countries. Reprod Health Matters 2010;18:158-70.

8 World Health Organisation (WHO). WHO Multi-country Study on Women's Health and Domestic Violence; initial results on prevalence, health outcomes and women's responses. Geneva: World Health Organization, 2005. http://apps.who.int/iris/bitstream/10665/43310/ 1/9241593512_eng.pdf

9 Bailey BA. Partner violence during pregnancy: prevalence, effects, screening, and management. Int J Womens Health 2010;2:183-97.

10 Shamu S, Abrahams N, Temmerman M, et al. A systematic review of African studies on intimate partner violence against pregnant women: prevalence and risk factors. PLoS One 2011;6:e17591.
11 Gebrezgi BH, Badi MB, Cherkose EA, et al. Factors associated with intimate partner physical violence among women attending antenatal care in Shire Endaselassie town, Tigray, Northern Ethiopia: a cross-sectional study, July 2015. Reprod Health 2017; 14 .

12 Owaka IO, Nyanchoka MK, Atieli HE. Intimate partner violence in pregnancy among antenatal attendees at health facilities in West Pokot County, Kenya. Pan Afr Med J 2017;28.

13 Ayodapo AO, Sekoni OO, Asuzu MC. Pattern of intimate partner violence disclosure among pregnant women attending ante-natal clinic in Oyo East local government, Nigeria. South African Family Practice 2017;59:67-71.

14 Nasir K, Hyder AA. Violence against pregnant women in developing countries: review of evidence. Eur J Public Health 2003;13:105-7.

15 Orpin J, Papadopoulos C, Puthussery S. The prevalence of domestic violence among pregnant women in Nigeria: a systematic review. Trauma Violence Abuse 2017:152483801773157.

16 Kaye DK, Mirembe FM, Bantebya G, et al. Domestic violence during pregnancy and risk of low birthweight and maternal complications: a prospective cohort study at Mulago Hospital, Uganda. Trop Med Int Health 2006;11:1576-84.

17 Kaye D, Mirembe F, Bantebya G. Risk factors, nature and severity of domestic violence among women attending antenatal clinic in Mulago Hospital, Kampala, Uganda. Cent Afr J Med 2002;48:64-8.

18 Dolan C. Understanding war and its continuation: the case of northern Uganda [PhD Thesis]. University of London, 2005.

19 Uganda Bureau of Statistics (UBOS) and ICF. Uganda demographic and health survey 2011. Kampala, Uganda and Rockville, Maryland, USA: UBOS and ICF, 2012.

20 Uganda Bureau of Statistics (UBOS) and ICF. Uganda demographic and health survey 2016. Kampala, Uganda and Rockville, Maryland, USA: UBOS and ICF, 2018.

21 Bartlett AL, Dhizaala JT. Post-Conflict capitalism in northern Uganda. Peace Review 2018;30:168-75.

22 Ameh N, Abdul M. Prevalence of domestic violence amongst pregnant women in Zaria, Nigeria. Ann Afr Med 2004;3:4-6.

23 Ansari U, Cobham B, Etim EM, et al. Insights into intimate partner violence in pregnancy: findings from a cross-sectional study in two states in Nigeria. Violence Against Women 2017;23:469-81.

24 Rasch V, Van TN, Nguyen HTT, et al. Intimate partner violence (IPV): the validity of an IPV screening instrument utilized among pregnant women in Tanzania and Vietnam. PLoS One 2018;13:e0190856.

25 Hoque ME, Hoque M, Kader SB. Prevalence and experience of domestic violence among rural pregnant women in KwaZulu-Natal, South Africa. South Afr J Epidemiol Infect 2009;24:34-7.

26 Jain S, Varshney K, Vaid NB, et al. A hospital-based study of intimate partner violence during pregnancy. Int J Gynecol Obstet 2017;137:8-13.

27 Islam MJ, Mazerolle P, Broidy L, et al. Exploring the prevalence and correlates associated with intimate partner violence during pregnancy in Bangladesh. $J$ Interpers Violence 2017:088626051773002.

28 Okello MC, Hovil L. Confronting the reality of gender-based violence in northern Uganda. Int J Transit Justice 2007;1:433-43. 